\title{
Early Prediction of Functional Outcome after Cerebral Small Arteries Infarctions Using Diffusion Tensor MRI Tractography
}

\author{
YASMEEN I. EL-SAYED MABROUK, M.Sc.*; RASHA A. EL-SHAFEY, M.D.**; \\ WAFIK S. BAHNASY, M.D.*** and MAHMOUD A. DAWOUD, M.D.** \\ The Department of Diagnostic Radiology, El-Menshawy General Hospital*, \\ The Departments of Diagnostic Radiology** and Neurology***, Faculty of Medicine, Tanta University
}

\begin{abstract}
Background: Lacunar Infarctions (LIs) are ischemic strokes caused by occlusion of the deep penetrating arteries. They constitute about $25 \%$ of all ischemic strokes and have variable consequences based on affected tracts disruptions.

Aim of Study: Were to assess the role of MRI Diffusion Tensor Imaging (DTI) fiber tractography as an early biomarker of LIs prognosis.

Patients and Methods: This work was conducted on 42 first-ever symptomatic motor or sensorimotor LIs patients (3 1 male and 11 female) submitted to stroke severity assessment using the National Institute of Health Stroke Scale (NIHSS), carotid duplex, brain MRI to determine LIs dimeter and occult small vessel disease imaging markers. Corticospinal Diffusion Tensor Tractography (CS-DTT) was done within 48 hours from stroke onset. Thirty-eight patients continued a 3-months follow-up schedule, at the end of which their physical dependences were assessed using the Modified Barthel Index (MBI) scale which were compared with the baseline assessment parameters to determine the prognostic biomarkers.
\end{abstract}

Results: Dependent patients' group showed significant increase in their age, BMI, carotid intima media thickness and white matter hyperintensities grade than independent patients' group. The FA ratio was the earliest parameter showed significant changes which were lower in dependent than independent patients' groups. On the other hand, each of ipsilateral DTI fractional anisotropy, mean diffusivity and fiber number showed non-significant differences.

Conclusion: Factors associated with poorer functional outcome after newly diagnosed LIs include advanced age, hypertension, obesity, premorbid physical inactivity, increased CIMT and the presence of imaging biomarkers of occult SVD. Reduced ipsilateral/contralateral FA ratio of the CS-DTT is a reliable early predictor of short-term functional outcome and motor disability after motor and sensorimotor LIs.

Key Words: Lacunar infarcts - Diffusion tensor imaging Corti co-spinal tractography - Modified barthel index - Post-stroke physical disabilities.

Correspondence to: Dr. Rasha A. El-Shafey, E-Mail: drrashaelshafey@yahoo.co.uk

\section{Introduction}

ISCHEMIC cerebrovascular stroke is defined as an episode of neurological dysfunction caused by focal cerebral, spinal or retinal infarction [1]. Stroke is the 2 nd cause of death worldwide, the 3 rd cause of prolonged disability and is responsible for $4.5 \%$ of Disability-Adjusted Life-Years (DALYs) from all medical causes globally [2] . Nearly $20 \%$ of stroke survivors are unable to return to work, $30 \%$ need daily living assistance and 16\% require institutional care [3] . Lacunar Infarctions (LIs) are small volume subcortical infarctions, $3-15 \mathrm{~mm}$ in diameter caused by occlusion of the small deep penetrating arteries. They may be occult LIs (asymptomatic) or clinically presented by either transient ischemic attacks or one of the lacunar syndromes including pure motor hemiparesis (the most common), pure sensory stroke, sensorimotor stroke, ataxic hemiparesis and dysarthria-clumsy hand syndrome $[4,5]$.

Diffusion Tensor Imaging (DTI) is a MRI sequence specifically evaluate the directionality and integrity of brain axonal fibers and networks strength in case of neuronal injury due to various etiologies including stroke. The data related to the

\footnotetext{
Abbreviations:

AADLs : Advanced Activities of Daily Living Scale.

ARWMC : Age-Related White Matter Changes.

CIMT : Carotid Intima Media Thickness.

CS-DTT : Corticospinal Diffusion Tensor Tractography.

DTI : Diffusion Tensor Imaging.

FA : Fractional Anisotropy.

FN : Fiber Number.

LIs : Lacunar Infarctions.

MBI : Modified Barthel Index

MD : Mean Diffusivity.

NIHSS : National Institute of Health Stroke Scale.

SVD : Small Vessel Disease.

WMHs : White Matter Hyperintensities.
} 
value of DTI in anticipating the degree of motor disabilities and functional outcome after corticospinal tract disruption due to cerebral infarction are contradictory [6].

\section{Patients and Methods}

This paper is adapted from the thesis with the same title submitted by the first author to the Faculty of Medicine, Tanta University, in partial fulfillment of the Master's Degree in Diagnostic Radiology. The work was a prospective study conducted on 42 patients (31 male and 11 female) with ${ }^{1 s t}$ ever symptomatic pure motor or sensorimotor LIs admitted to the Neurovascular Units and/or the ICUs of the Neurology Department, Tanta University Hospitals in the period from November 2017 till June 2018.

Exclusion criteria included patients received intravenous thrombolysis (to keep homogeneity of the studied sample) as well as patients with recurrent stroke, CADASIL disease, MRI contraindications, preexisting physical disability, cognitive impairment or psychiatric disorders. Vitally unstable patients and those with advanced renal, hepatic, chest or cardiac diseases were also excluded.

The study's protocol was approved by the Research Ethics Committee and Quality Assurance Unit, Faculty of Medicine, Tanta University. Participations were voluntary, informed consents were obtained from all included patients and the possible risks were clarified.

Patients were submitted to history taking, prestroke basic Activities of Daily Living (ADL) assessment using the Advanced Activities of Daily Living Scale (AADLs) [7], complete neurological examination and stroke severity assessment using the National Institute of Health Stroke Scale (NIHSS). The mean common Carotid Intima Media Thickness (CIMT) was measured by the calculating the average of multiple bilateral measurements in area away from atheromatous plaques (if present). The maneuver was done using linear array transducer of multi-frequency $3-12 \mathrm{MHz}$, real time, sagittal, coronal and axial views, Ultrasound Philips. Model: HD 11TM XE, Germany.

Brain MRI were done to confirm the diagnosis of recent LIs and determine their sizes as well as their locations. White Matter Hyperintensities (WMHs) were graded using the Age-Related White Matter Changes (ARWMC) visual rating scale (supplementary material-1) [8]. Brain MRI was performed using GE Healthcare, Milwaukee, WI,
USA. The images were attained by a 1.5-Tesla, General Electric Scanner (GE Medical Systems, Milwaukee, USA) with quadrature 8 channels head coil included axial T1 and T2 weighted fast spinecho, 3-D FLAIR, and diffusion weighted images (DWI) using strong gradient strength thigh bvalues $=1000$ seconds/millimeter $\left.2\left(\mathrm{~s} / \mathrm{mm}^{2}\right)\right]$ with estimation of the associated Apparent Diffusion Coefficient (ADC) value.

Corticospinal diffusion tensor tractography (CS-DTT) were done within 48 hours from stroke onset to measure the Fractional Anisotropy (FA), Mean Diffusivity (MD) and Fiber Number (FN) in the region of abnormality compared to the contralateral hemisphere. The DTI sequence was done by single-shot spin echo-planar imaging with TR $8830 \mathrm{msec}$., TE $80 \mathrm{msec}$., acquisition matrix $112 \mathrm{X}$ $110 \mathrm{~mm}$, acquisition voxel $2.00 / 2.03 / 2.00 \mathrm{~mm}$, field of view; right-left $224 \mathrm{~mm}$, anteroposterior $224 \mathrm{~mm}$ and feet-head $120 \mathrm{~mm}$, voxel size; right-left $2 \mathrm{~mm}$, anteroposterior $2 \mathrm{~mm}$ and slice thickness $2 \mathrm{~mm}$, reconstruction voxel size $1.75 \mathrm{~mm}$, gradient direction 32 , b-value $1000 \mathrm{~mm} / \mathrm{s}$ and number of slices was 60 with total scan time 9:51 minutes.

Patients continued a followed-up schedule for 3 months, at the end of which the degree of physical dependence on exerting their ADL were assessed using the Modified Barthel Index (MBI) scale. Four patients dropped out the follow-up and the remaining 38 continued and accordingly they were divided to 3 groups; 11 moderately dependent patients attained $\leq 90$ points (Group-I), 21 slightly dependent cases achieved 91-99 points (Group-II) and 6 independent patients scored 100 in MBI (Group-III). The MBI score was compared with the baseline assessed parameters to determine their values as prognostic biomarkers.

Statistical analysis was conducted using SPSS Prism, Version 20, 2013 created by IBM, Illinois, and Chicago, USA. Differences between the studied groups were tested using Chi-square, ANOVA and TUKEY'S tests. Correlation analysis was performed using Pearson's correlation test. $p$-value $<0.05$ was considered statistically significant.

\section{Results}

Baseline evaluation of the included 42 LIs patients showed that their mean age was $61.38 \pm 4.44$ years, 22/42 (52.4\%) were females, 20/42 (47.6\%) were males, BMI was $31.07 \pm 2.7 \mathrm{~kg} / \mathrm{m}^{2}$, the AADLs was $25.64 \pm 5.56$ points, $19 / 42(45.24 \%)$ were hypertensives, $12 / 42(28.6 \%)$ were diabetics, 11/42 (26.2\%) were smokers, 9/42 (21.4\%) had dyslipi- 
demia, 4/42 (9.5\%) had ischemic heart diseases and $2 / 42(4.8 \%)$ had atrial fibrillation. The mean CIMT was $1.22 \pm 0.34 \mathrm{~mm}$ and the NIHSS was $14.1 \pm$ 1.81 points. Thirty-six $(85.7 \%)$ of the studied patients were pure motor and the remaining 6/42 $(14.3 \%)$ were mixed sensorimotor LIs syndromes. Regarding the recent infarcts localization, 34/36 of pure motor and all sensorimotor LIs patients had infarctions in the posterior limb of the internal capsule with some thalamic extension in sensorimotor cases. Two of pure motor LIs patients had pontine infarctions. The lacunes' diameters were $9.34 \pm 2.03 \mathrm{~mm}$, the ARWMC score was $7.36 \pm 3.1$ points and 14/42 (33.3\%) had 1-3 old occult LIs.

The results of the present study showed that each of ipsilateral and contralateral FA were $0.296 \pm$ 0.126 and $0.376 \pm 0.155$ with FA ratio $0.83 \pm 0.098$. At the same time, the ipsilateral and contralateral MD were $0.578 \pm 0.17$ and $0.801 \pm 0.07$ while the FN were $212.03 \pm 65.2$ and $298.92 \pm 70.91$ respectively.

The results showed that, the ages of the moderately and slightly dependent patients' groups were non-significantly different $(p$-value $=0.226)$, but both groups were older than the independent group with $p$-values 0.003 and 0.038 respectively. The moderately dependent patients' group showed significant increase in the BMI, CIMT and existence of HTN than slightly dependent and independent patients' groups with $p$-values 0.05 . At the same time, the moderately dependent group was significantly lower both other groups regarding the prestroke AADL score. On the other hand, the 3 studied groups showed non-significant difference regarding the NIHSS, patients' sex and lacunar diameters as well as the existence of DM, dyslipidemia and smoking Tables $(1,2)$.

Regarding CS-DTT the 3 studied groups showed non-significant differences regarding the ipsilateral as well as contralateral FA, MD and FN with $p$ values 0.05 . On the other hand, the FA ratio was significantly lower in moderately dependent than slightly dependent patients' groups ( $p$-value 0.001$)$ and both showed significantly reduced ratio compared to independent patients' groups with $p$-value 0.001 (Table 2), Figs. $(1,2)$.

The present results stated that the MBI scale was negatively correlated with the patients' age, BMI, smoking index, ARWMC score, occult LIs number, CIMT, and lacunar infarction diameters with $p$-values 0.05 . At the same time, MBI scale was positively correlated with each of AADLs and FA ratio ( $p$-value 0.05 ). On the other hand, the MBI scale showed no correlation with the baseline NIHSS and each of ipsilateral as well as contralateral FA, MD and FN (Table 3), Fig. (3).

Table (1): Comparison between Group I (moderately dependent patients), Group II (slightly dependent) and Group III (independent) regarding the existence of some vascular risks of stroke.

\begin{tabular}{|c|c|c|c|c|c|c|}
\hline & \multirow{2}{*}{$\begin{array}{c}\text { Group I } \\
(\mathrm{n}: 11)\end{array}$} & \multirow{2}{*}{$\begin{array}{c}\text { Group II } \\
(\mathrm{n}: 21)\end{array}$} & \multirow{2}{*}{$\begin{array}{c}\text { Group III } \\
(\mathrm{n}: 6)\end{array}$} & \multirow{2}{*}{$\begin{array}{c}\text { Total } \\
\text { (n:38) }\end{array}$} & \multicolumn{2}{|c|}{ Chi-square } \\
\hline & & & & & $x^{2}$ & $p$-value \\
\hline \multicolumn{7}{|l|}{ Sex: } \\
\hline Male & $6(55)$ & $12(57)$ & $1(17)$ & $19(50)$ & 3.186 & 0.203 \\
\hline Female & $5(45)$ & $9 \quad(43)$ & $5(83)$ & $19(50)$ & & \\
\hline \multicolumn{7}{|c|}{ Hypertension: } \\
\hline Present & $8(73)$ & $9 \quad(43)$ & $0(0.0)$ & $17(45)$ & 8.373 & $0.015^{*}$ \\
\hline Absent & $3(27)$ & $12(57)$ & $6(100)$ & $21(55)$ & & \\
\hline \multicolumn{7}{|l|}{ Diabetes: } \\
\hline Present & $5(45)$ & $6 \quad(29)$ & $0(0.0)$ & $11(29)$ & 3.903 & 0.142 \\
\hline Absent & $6(55)$ & $15(71)$ & $6(100)$ & $27(71)$ & & \\
\hline \multicolumn{7}{|c|}{ Dyslipidemia: } \\
\hline Present & $3(27)$ & $5 \quad(24)$ & $0(0.0)$ & $8 \quad(21)$ & 1.952 & 0.377 \\
\hline Absent & $8(73)$ & $16(76)$ & $6(100)$ & $30(79)$ & & \\
\hline \multicolumn{7}{|l|}{ Smokers: } \\
\hline Present & $6(55)$ & $4 \quad(19)$ & $1(17)$ & $11(19)$ & 4.945 & 0.084 \\
\hline Absent & $5(45)$ & $17(81)$ & $5(83)$ & $27(71)$ & & \\
\hline
\end{tabular}

*: Significant. 
Table (2): Comparison between Group I (moderately dependent patients), Group II (slightly dependent) and Group III (independent) regarding the existence of some vascular risks of stroke.

\begin{tabular}{|c|c|c|c|c|c|c|c|c|}
\hline & \multirow{2}{*}{$\begin{array}{l}\text { Group I } \\
(\mathrm{n}: 11)\end{array}$} & \multirow{2}{*}{$\begin{array}{l}\text { Group II } \\
(\mathrm{n}: 21)\end{array}$} & \multirow{2}{*}{$\begin{array}{l}\text { Group III } \\
\text { (n:6) }\end{array}$} & \multicolumn{2}{|c|}{ ANOVA } & \multicolumn{3}{|c|}{ TUKEY'S test } \\
\hline & & & & f-value & $p$-value & I vs. II & I vs. II & II vs. III \\
\hline Age & $63.5 \pm 3.2$ & $61.0 \pm 4.4$ & $56.3 \pm 3.3$ & 6.404 & $0.004 *$ & 0.226 & $0.003 *$ & $0.038^{*}$ \\
\hline BMI & $33.5 \pm 1.5$ & $29.8 \pm 2.5$ & $30.7 \pm 2.4$ & 9.924 & $<0.001^{*}$ & $<0.001 *$ & $0.044^{*}$ & 0.694 \\
\hline ARWMC & $11.2 \pm 1.7$ & $6.5 \pm 2.0$ & $3.8 \pm 0.8$ & 39.116 & $<0.001 *$ & $<0.001 *$ & $<0.001 *$ & $0.007 *$ \\
\hline Occult LBIs number & $1.8 \pm 0.8$ & $1.1 \pm 0.6$ & $0.2 \pm 0.4$ & 13.203 & $<0.001 *$ & $0.012^{*}$ & $<0.001 *$ & $0.009 *$ \\
\hline NIHSS & $14.3 \pm 2.5$ & $14.3 \pm 1.5$ & $14.0 \pm 1.4$ & 0.078 & 0.925 & & & \\
\hline AADLs & $20.5 \pm 3.8$ & $27.4 \pm 4.4$ & $31.2 \pm 3.9$ & 15.744 & $<0.001^{*}$ & $<0.001 *$ & $<0.001 *$ & 0.133 \\
\hline Carotid IMT & $1.6 \pm 0.2$ & $1.1 \pm 0.3$ & $0.9 \pm 0.2$ & 24.038 & $<0.001^{*}$ & $<0.001 *$ & $<0.001 *$ & 0.094 \\
\hline Lacunar diameter & $9.9 \pm 2.8$ & $9.1 \pm 1.9$ & $8.8 \pm 1.2$ & 0.718 & 0.495 & - & - & - \\
\hline Ipsilateral FA & $0.32 \pm 0.14$ & $0.28 \pm 0.12$ & $0.32 \pm 0.14$ & 0.492 & 0.616 & - & - & - \\
\hline Contralateral FA & $0.47 \pm 0.17$ & $0.35 \pm 0.14$ & $0.32 \pm 0.14$ & 2.919 & 0.067 & & & \\
\hline FA ratio & $0.67 \pm 0.084$ & $0.80 \pm 0.078$ & $0.99 \pm 0.132$ & 26.084 & $<0.001^{*}$ & $0.001 *$ & $<0.001 *$ & $<0.001 *$ \\
\hline Ipsilateral MD & $0.55 \pm 0.04$ & $0.59 \pm 0.08$ & $0.57 \pm 0.06$ & 1.763 & 0.186 & - & - & - \\
\hline Contralateral MD & $0.81 \pm 0.06$ & $0.79 \pm 0.07$ & $0.83 \pm 0.07$ & 0.713 & 0.497 & - & - & - \\
\hline Ipsilateral FN & $190 \pm 36.3$ & $223 \pm 74$ & $211 \pm 74$ & 0.964 & 0.391 & - & - & - \\
\hline Contralateral FN & $293 \pm 61$ & $303 \pm 83$ & $298 \pm 45$ & 0.071 & 0.931 & - & - & - \\
\hline FN ratio & $0.66 \pm 0.05$ & $0.73 \pm 0.09$ & $0.70 \pm 0.16$ & 2.509 & 0.096 & & & \\
\hline MBI & $82.0 \pm 3.0$ & $94.3 \pm 2.6$ & $100 \pm 0.0$ & 125.063 & $<0.001^{*}$ & $<0.001 *$ & $<0.001 *$ & $<0.001 *$ \\
\hline \multicolumn{9}{|l|}{ * $\quad$ : Significant. } \\
\hline \multirow{2}{*}{\multicolumn{9}{|c|}{$\begin{array}{l}\text { AADLs : Advanced Activities of Daily Living Scale. } \\
\text { ARWMC : Age-Related White Matter Changes Scale. }\end{array}$}} \\
\hline & & & MD & & & & & \\
\hline \multicolumn{3}{|c|}{$\begin{array}{l}\text { ARWMC : Age-Related White Matter Changes Scale. } \\
\text { BMI : Body Mass Index. }\end{array}$} & FN & Fiber Numb & & & & \\
\hline \multirow{2}{*}{\multicolumn{3}{|c|}{$\begin{array}{l}\text { IMT } \\
\text { FA Intima Media Thickness. }\end{array}$}} & NIHSS : & National In & tute of Healt & Stroke Scale & & \\
\hline & & & & & & & & \\
\hline
\end{tabular}
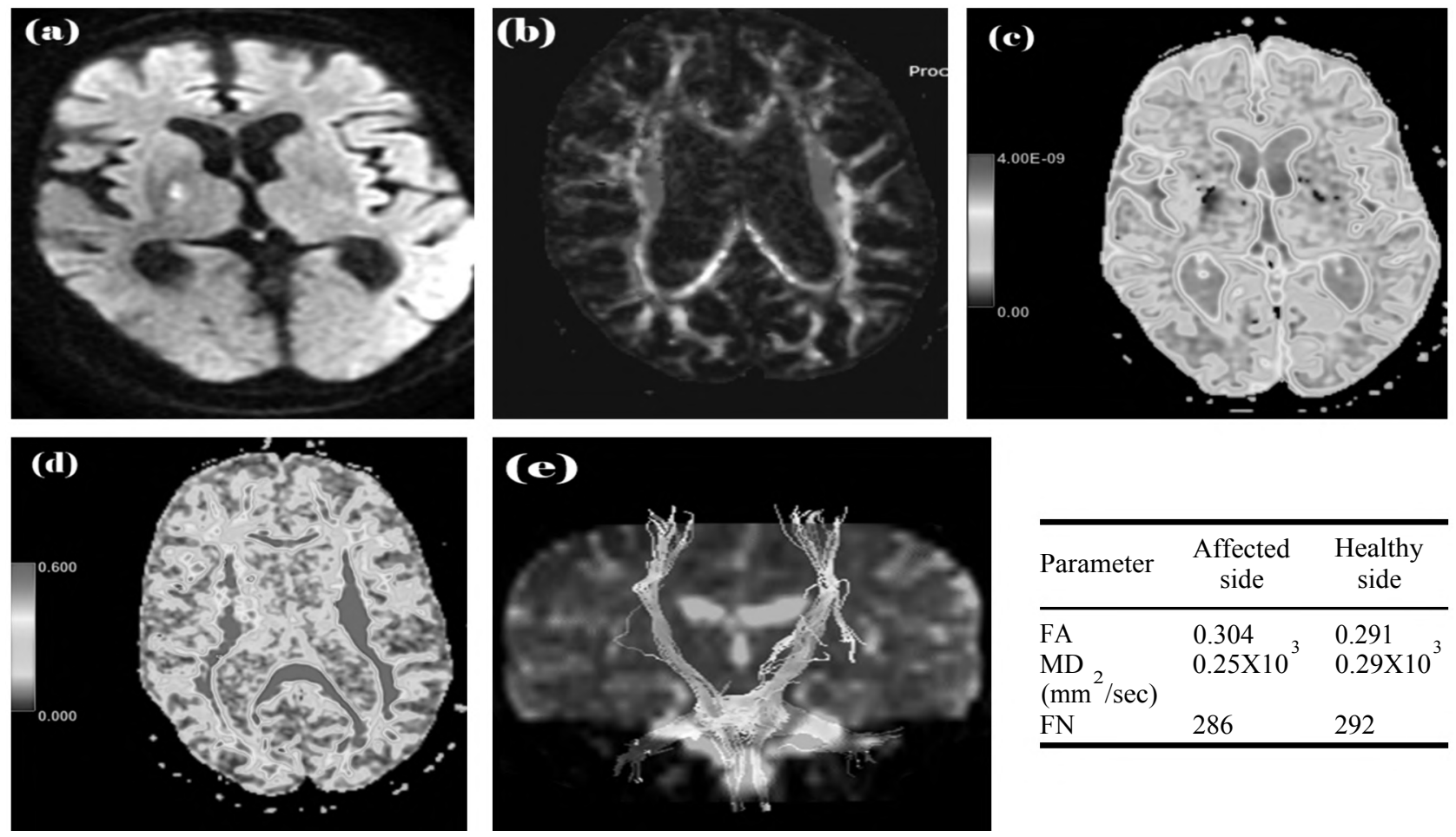

\begin{tabular}{lll}
\hline Parameter & $\begin{array}{c}\text { Affected } \\
\text { side }\end{array}$ & $\begin{array}{l}\text { Healthy } \\
\text { side }\end{array}$ \\
\hline $\mathrm{FA}$ & 0.304 & 0.291 \\
$\left.\mathrm{MD}_{2}{ }^{2} / \mathrm{sec}\right)$ & $0.25 \times 10^{3}$ & $0.29 \times 10^{3}$ \\
$\mathrm{FN}^{\mathrm{FN}}$ & 286 & 292 \\
\hline
\end{tabular}

Fig. (1): An included 61-year-old male presented by left pure motor lacunar syndrome with admission NIHSS was 13 points and the 3-months MBI was 86 points (moderately dependent). The MRI images revealed (A) DWI showed lacunar infarction in the genu and posterior limb of the internal capsule, (B) The color-coded map showed normal CST (blue in color), (C) Decreased MD of the ipsilateral CST, (D) Increased FA at infarction site, and (E) Normal course and fiber number of the CST 3-d fiber tractography.

CST : Corticospinal Tract.

DWI: Diffusion Weighted Image.
FA: Fractional Anisotropy.

FN: Fiber Number.
MBI : Modified Barthel Index.

NIHSS: National Institute of Health Stroke Scale. 

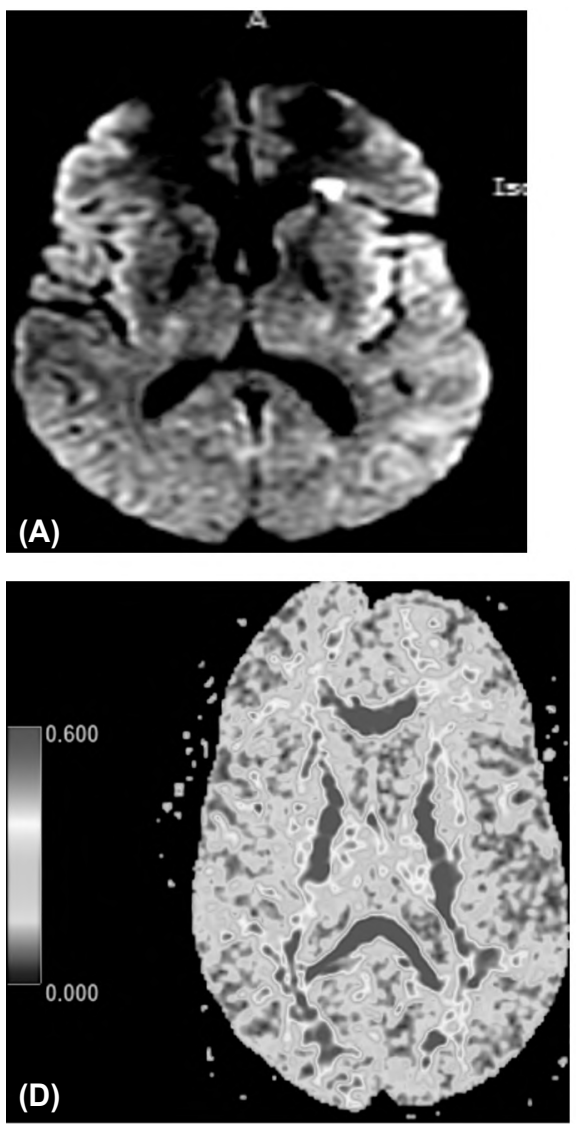
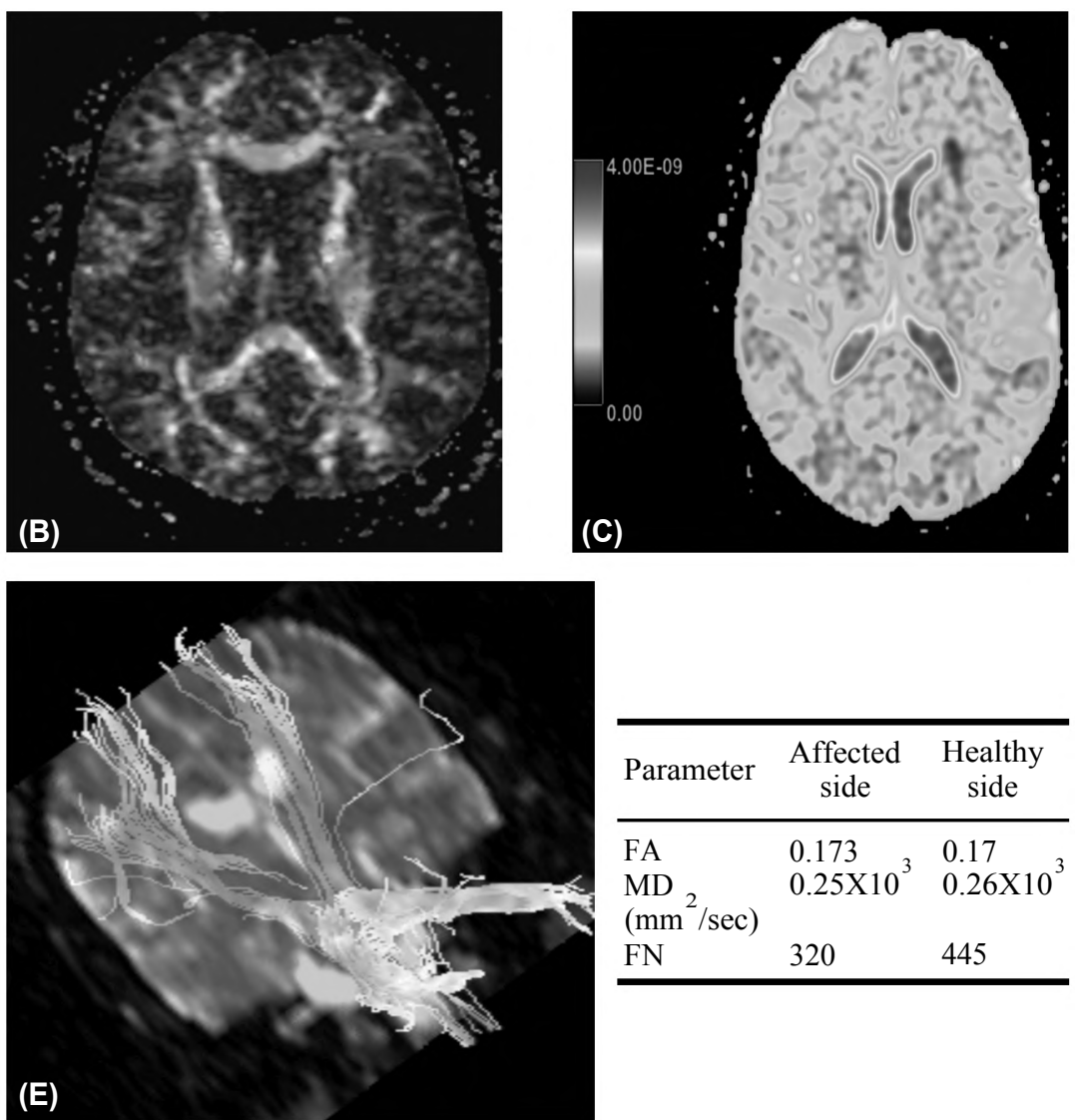

\begin{tabular}{lll}
\hline Parameter & $\begin{array}{c}\text { Affected } \\
\text { side }\end{array}$ & $\begin{array}{l}\text { Healthy } \\
\text { side }\end{array}$ \\
\hline $\mathrm{FA}$ & 0.173 & 0.17 \\
$\mathrm{MD}^{2}$ & $0.25 \times 10^{3}$ & $0.26 \times 10^{3}$ \\
$\mathrm{~mm}^{2}$ & 320 & 445 \\
\hline
\end{tabular}

Fig. (2): An included fifty six years old female patient admitted with acute lacunar infarction at the left periventricular region with admission NIHSS was 13 points and the 3 -months MBI was 88 points (moderately dependent). The MRI images revealed (A) DWI showed recent infarction at the left periventricular region, (B) The color-coded map showed mild distortion of left CST at the left periventricular region (blue in color), (C) Decreased MD of the ipsilateral CST, (D) Increased FA at infarction site and (E) Attenuated with decreased fibre number of left CST 3-d fiber tractography.

CST : Corticospinal Tract.

DWI: Diffusion Weighted Image.
FA: Fractional Anisotropy. FN: Fiber Number.
MBI : Modified Barthel Index.

NIHSS: National Institute of Health Stroke Scale.
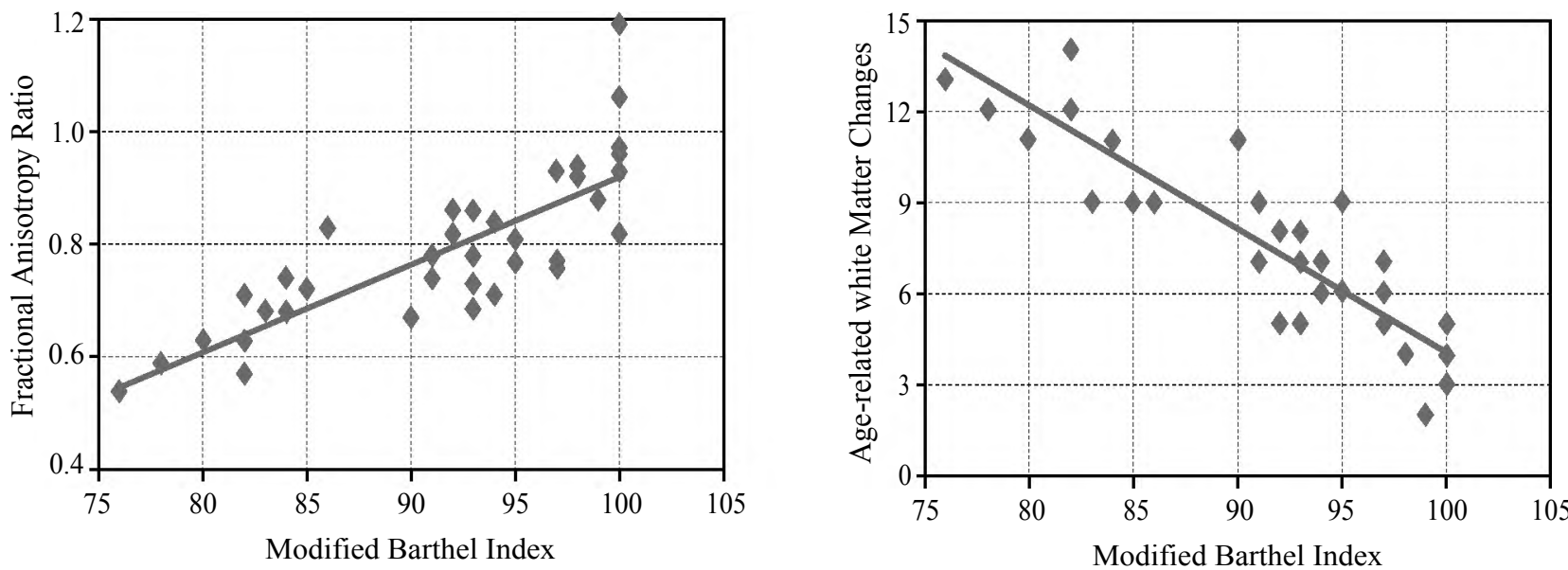

Fig. (3): The Modified Barthel index if positively correlated with fractional anisotropy ratio (Left) and negatively correlated with the age-related white matter changes scale (Right) among the studied lacunar infarction patients. 
Table (3): Correlation of modified barthel index score in included lacunar infarction patients 3-months after stroke onset with other studied baseline parameters.

\begin{tabular}{lcl}
\hline & \multicolumn{2}{c}{ Modified Barthel Index } \\
\cline { 2 - 3 } & $r$ & $p$-value \\
\hline Age & -0.572 & $<0.001^{*}$ \\
BMI & -0.407 & $0.011^{*}$ \\
ARWMC & -0.909 & $<0.001^{*}$ \\
Occult LBIs & -0.722 & $<0.001^{*}$ \\
NIHSS & -0.103 & 0.540 \\
AADLs & 0.692 & $<0.001^{*}$ \\
Cartid IMT & -0.798 & $<0.001^{*}$ \\
Lacunar diameter & -0.338 & $0.038^{*}$ \\
Ipsilateral FA & 0.140 & 0.403 \\
Contralateral FA & -0.177 & 0.289 \\
FA ratio & 0.801 & $<0.001 *$ \\
Ipsilateral MD & 0.234 & 0.158 \\
Contralateral MD & 0.099 & 0.553 \\
Ipsilateral FN & 0.197 & 0.235 \\
Contralateral FN & 0.095 & 0.570 \\
FN ratio & 0.238 & 0.150 \\
* : Significant. & \\
AADLs $\quad$ : Advanced Activities of Daily Living Scale. \\
ARWMC : Age-Related White Matter Changes Scale. \\
BMI : Body Mass Index. \\
IMT : Intima Media Thickness. \\
FA : Fractional Anisotropy. \\
LBIs : Lacunar Brain Infarctions. \\
MBI : Modified Barthel Index. \\
MD : Mean Diffusivity. \\
FN : Fiber Number. \\
NIHSS : National Institute of Health Stroke Scale. \\
\multicolumn{2}{|}{}
\end{tabular}

\section{Discussion}

Lacunar strokes are small subcortical brain infarctions constituting about $25 \%$ of all ischemic strokes and despite their lower mortality rates, they result in moderately severe neurological deficit, increased disabilities and delayed recovery due to their deleterious effects on brain network circuits [9]. Accurate early prediction of the motor deficit after LIs is crucial to design suitable management and rehabilitation programs, minimizes neurological deficits and facilitates functional recovery. Tissue edema and mass effect may be responsible for increased motor deficit in early post-stroke period which makes reliability on clinically based biomarkers imprecise and need additional neuroimaging tools to assess corticospinal neurophysiological and structural integrity [10].

The study showed that, symptomatic LIs were more common among elderly and old age was a bad prognostic factor associated with delayed and incomplete physical rehabilitations. These results are in accordance with the work of TorrealbaAcosta et al., 2018 [11] who found that advanced age is a non-modifiable risk factor for LIs associated with higher morbidity and mortality rates. On the other hand, these results are not in harmony with the work of Cai et al., 2016 [12] who concluded that the age per se is not a bad prognostic factor, but the age related vascular risks including hypertension, diabetes and cardiovascular diseases are the cause of LIs poor functional outcome. These results differences were possibly due to inclusion of many occult asymptomatic LIs patients in their studied cases.

The results also, declared that hypertension is associated with delayed recovery of LIs patients which is in accordance with the thesis of Fukui et al., [13] and Smith et al., 2017 [14] who specified that common vascular risks including hypertension is a poor prognostic factors in strokes of elderly. The results also, displayed that obesity and physical inactivity are common stroke risks and associated with significantly higher post-stroke disability in short-term LIs outcome which is passing with the work of Howard and McDonnell, 2015 [15] who declared that healthy life-style, weight control and regular exercises are well documented modifiable risk factors associated with good prognosis after LIs through accompanied consumption of healthy diets, weight control and better vascular risks control (hypertension, DM and smoking).

The study also showed that, increased CIMT is associated with poorer prognosis and lesser functional outcome. These results agree with the work of Song et al., 2018 [16] who declared that increased CIMT was an independent risk of LIs and associated with poorer outcome due to its high association with vascular risks and increased tissue inflammatory markers. On the contrary, Polak and O'Leary, 2016 [17] stated that increased CIMT may not associated with higher LIs induced motor disability as it is more related to large vessel atherosclerosis than Small Vessel Disease (SVD). At the same time, the present study stated that the presence of occult SVD imaging markers as WMHs and occult LIs are associated with higher motor disabilities after symptomatic LIs which is in agreement with the work of El-Senousy et al., 2013 [18] and Ferguson et al., 2018 [19] who concluded that, the presence of covert SVD especially leukoaraiosis is associated with poor functional and cognitive outcome after symptomatic stroke.

Diffusion tensor imaging is a technique that enables quantitative estimation of tissue microstructure based on diffusivity properties of Brownian water molecules motions which makes it able to reconstruct a 3D macroscopic orientation and visualize the white matter tracts integrity within 
the infarcted area and thus anticipate the degree of recovery [20]. The study showed that decreased ipsilateral/contralateral FA ratio of CS-DTT was an early sensitive biomarker predicting post-stroke functional outcome and motor disability after motor and sensorimotor LIs. At the same time, early assessed ipsilateral and contralateral FA, MD and FN showed non-significant differences between dependent and independent patients' groups possibly due to their wide range of normality resulted in statistically non-significant differences and their need of longer durations to show significantly reliable changes. These results are in accordance with the work of Elkholy et al., 2015 [21] who concluded that reduced early post-stroke FA ratio is an indicator of irreversible tissue damage and more sensitive than the clinically based NIHSS as the latter may be elevated by the tissue edema and mass effect rather than axonal damage, but their study differed from the present one in DTI procedure timing (1-week after stroke onset) and inclusion of patients with widely different NIHSS range. These differences resulted in recording a reduced ipsilateral FA in the dependent than independent patients' groups. In a parallel way, the present results were in harmony with the work of Alegiani et al., 2017 [22] who reported non-significant changes in early ipsilateral FA between dependent and independent patients' groups due to its diverse changes which was decreased in a sector of patients and increased in another. On the other hand, Puig et al., 2013 [23] stated that early FA increase is a surrogate marker of motor deficit after stroke and they did not report significant reduction of FA ratio at 12 hours and 7 days assessment which became significantly reduced in the 30th day post-stroke DTI assessment. The latter was an important independent predictor of long-term motor outcome after occlusive stroke. The cause of these differences is the heterogeneity of their included patients with large and small arteries infarctions, had nonmotor lacunar syndromes and received intravenous thrombolysis who were in the exclusion criteria of the present study. In contrast to the results of this study, the work of Abdeldayem et al., 2017 [24] delineated the presence of significant decrease in FA and pyramidal tract FN inside the infarcted area possibly due to undergoing the DTI after 2 weeks from stroke onset at which the infarction showed subacute changes.

\section{Limitations:}

The short-term period of follow-up and the need of post-stroke cognitive impairment assessment. Non-inclusion of pure sensory, ataxic hemiparesis and dysarthria clumsy hand lacunar syn- dromes as the localizations of their lesions are away from the examined CS-DTT.

Acknowledgement: We would like to thank the Neurology and Chest Departments Staff, Faculty of Medicine, Tanta University for their great help in patients' selection, and humbling obstacles during case assessments.

\section{References}

1- SACCO R.L., KASNER S.E., BRODERICK J.P., et al. An updated definition of stroke for the 21 st century. Stroke, 44 (7): 2064-89, 2013.

2- FEIGIN V.L., NORRVING B. and MENSAH G.A.: Global Burden of Stroke. Circ. Res., 120: 439-48, 2017.

3- FEIGIN V.L., ROTH G.A., NAGHAVI M., PARMAR P., KRISHNAMURTHI R., CHUGH S., et al.: Global burden of stroke and risk factors in 188 countries, during 19902013: A systematic analysis for the Global Burden of Disease Study 2013. Lancet Neurology, 24: 15-24, 2016.

4- VAN VELUW S.J., SHIHN A.Y., SMITH E.E., CHEN C., SCHNEIDER J.A., WARDLAW J.M., et al.: Detection, risk factors, and functional consequences of cerebral microinfarcts. Lancet Neurol., 16: 730-40, 2017.

5- YAN B., PENG L., DONG Q., ZHENG F., YANG P., SUN L., GONG S., ZENG L. and WANG G.: Reversedipper pattern of blood pressure may predict lacunar infarction in patients with essential hypertension. Eur. J. Neurol., 22 (6): 1022-5, 2015.

6- PUIG J., BLASCO G., SCHLAUG G., et al.: Diffusion tensor imaging as a prognostic biomarker for motor recovery and rehabilitation after stroke. Neuroradiology, 59 (4): 343-51, 2017.

7- DIAS E.N., Da SILVA J.V., PAIS-RIBEIRO J.L. and MARTINS T.: Validation of the advanced activities of daily living scale. Geriatric Nursing, in press, 2018.

8- WAHLUND L.O., BARKHOF F., FAZEKAS F., BRONGE L., AUGUSTIN M., SJÖGREN M., et al.: A New Rating Scale for Age-Related White Matter Changes Applicable to MRI and CT. Stroke, 32: 1318-22, 2001.

9- CAO W., YASSI N., SHARMA G., YAN B., DESMOND P.M., DAVIS S.M., et al.: Diagnosing acute lacunar infarction using CT perfusion. Journal of Clinical Neuroscience, 29: 70-2, 2016.

10- LIN C.C., TSAI M.Y., LO Y.C., LIU Y.J., TSAI P.P., WU C.Y., et al.: Reproducibility of corticospinal diffusion tensor tractography in normal subjects and hemiparetic stroke patients. Eur. J. Radiol., 82 (10): e610-6, 2013.

11- TORREALBA-ACOSTA G., CARAZO-CÉSPEDES K., CHIOU S.H., O'BRIEN A.T. and FERNÁNDEZMORALES H.: Epidemiology of Stroke in Costa Rica: A 7-Year Hospital-Based Acute Stroke Registry of 1319 Consecutive Patients. Journal of Stroke and Cerebrovascular Diseases, 27 (5): 1143-52, 2018.

12- CAI Z., HE W., PENG C., ZHOU J., XU Q. and WU Z. The prevalence of lacunar infarct decreases with aging in the elderly: A case-controlled analysis. Clin. Interv. Aging., 11: 733-8, 2016. 
13- FUKUI S., IMAZEKI R., AMANO Y., KUDO Y., AMARI K., YAMAMOTO M., et al.: Common and specific risk factors for ischemic stroke in elderly: Differences based on type of ischemic stroke and aging. Journal of the Neurological Sciences, 380: 85-91, 2017.

14- SMITH E.E., SAPOSNIK G., BIESSELS G.J., DOUBAL F.N., FORNAGE M., GORELICK P.B., et al.: Prevention of Stroke in Patients with Silent Cerebrovascular Disease: A Scientific Statement for Healthcare Professionals from the American Heart Association/American Stroke Association. Stroke, 48 (2): e44-e71, 2017.

15-HOWARD V.J. and McDONNELL M.N.: Physical Activity in Primary Stroke Prevention Just Do It! Stroke, 46: 17359, 2015.

16- SONG P., XIA W., ZHU Y., WANG M., CHANG X., JIN S., et al.: Prevalence of carotid atherosclerosis and carotid plaque in Chinese adults: A systematic review and metaregression analysis. Atherosclerosis, 276: 67-73, 2018.

17- POLAK J.F. and O'LEARY D.H.: Carotid Intima-Media Thickness as Surrogate for and Predictor of CVD. Global Heart, 11 (3): 295-312, 2016.

18- EL-SENOUSY M.Y., KHALIL M.K., BAHNASY W.S., EL-HENEEDY Y.A., HASSANIEN O.A. and ELSHAFEY R.: Leukoaraiosis as a Predictor of Short Term Outcome of Acute Ischemic Stroke. Egypt J. Neurol. Psychiat. Neurosurg., 50 (3): 339-45, 2013.

19- FERGUSON K.J., CVORO V., MacLULLICH A.M.J., SHENKIN S.D., SANDERCOCK P.A.G., SAKKA E. and
WARDLAW J.M.: Visual Rating Scales of White Matter Hyperintensities and Atrophy: Comparison of Computed Tomography and Magnetic Resonance Imaging. Journal of Stroke and Cerebrovascular Diseases, 27 (7): 181521, 2018.

20- DUBEY P., LIOUTAS V.A., BHADELIA R., MANOR B., NOVAK P., SELIM M., et al.: Quantitative microstructural deficits in chronic phase of stroke with small volume infarcts: A diffusion tensor 3-D tractographic analysis. Magnetic Resonance Imaging, 34: 662-7, 2016.

21- ELKHOLY S.F., KHALIL M.E., ELBASMI A.A., MAHMOUD B.E.M.H. and EDREES M.: Diffusion tensor magnetic resonance imaging in assessment of prognostic outcome of stroke patients. The Egyptian Journal of Radiology and Nuclear Medicine, 46: 707-13, 2015.

22- ALEGIANI A.C., MacLEAN S., BRAASS H., SIEMONSEN S., GERLOFF C., FIEHLER J., et al.: Comprehensive analysis of early fractional anisotropy changes in acute ischemic stroke. PLoS ONE, 12 (11): e0188318, 2017.

23- PUIG J., BLASCO G., DAUNIS-I-ESTADELLA J., THOMALLA G., CASTELLANOS M., FIGUERAS J., et al.: Decreased Corticospinal Tract Fractional Anisotropy Predicts Long-term Motor Outcome After Stroke. Stroke, 44: 2016-18, 2013.

24- ABDELDAYEM E.A., OSMAN A.M. and ROUSHDY T.M.: Relative fractional anisotropy value using DTI: Can it help as a prognostic tool in anticipating the recovery of stroke patients? The Egyptian Journal of Radiology and Nuclear Medicine, 48: 1019-25, 2017.

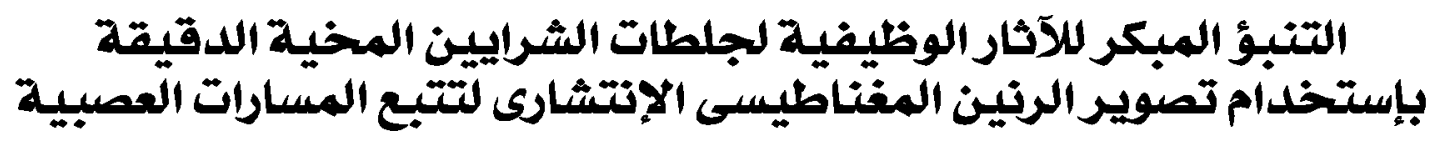

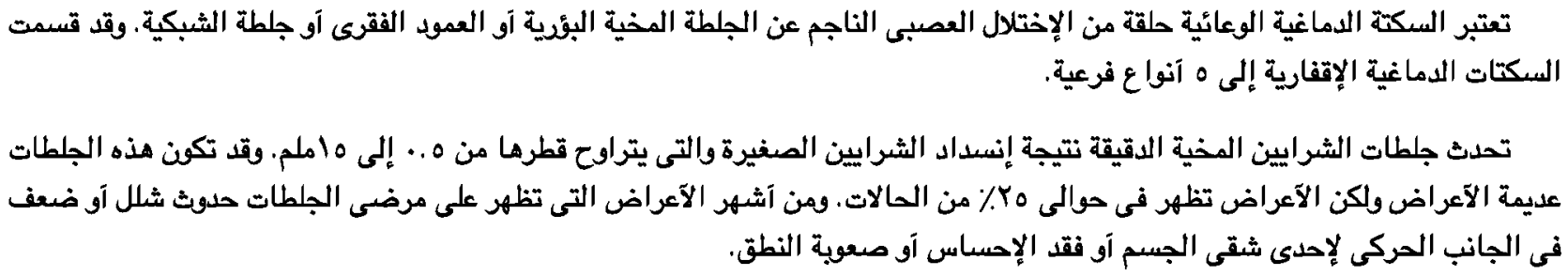

على الرغم من تصسن العلاج، فإن معظم المرضى يعانون من العجز الصركى بعد السكتة الدماغية، وغالبا ما تسبب الإعاقة. ومن شآن التبئّ

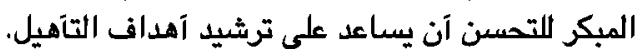

تعتمد إعتمادا كبيرا على القاة القشرية النخاعية هي المسار الرئيسى الذيى يتوبسط الحركات الإرادية، وقد آثبت التصوير العصبى والهيكلى آن حركة المريض

يلعب التصوير بالرنين المغناطيسى دوا باصذا على نحو متزايد ليس فقط فى تحديد الإصابات الدماغية، ولكن آيضا في تحديد العلاقة

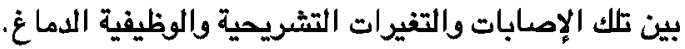

هنالك طرق حديثة تم تطويرها التى لم تلخل بعد المجال الإكلينيكي الروتينى. التصوير بالرنين المغناطيسى الإنتشارى وتتبع المسارات

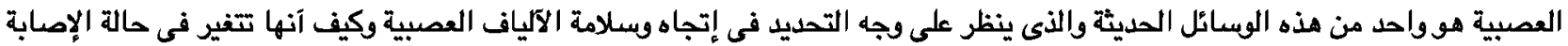
العصبية بسبب آسباب مختلفة منها السكثة الدماغية. 